\title{
On the effects of regional accents on memory and credibility
}

\author{
Candice Frances
}

Albert Costa ${ }^{\mathrm{a}, \mathrm{b}, *}$

costalbert@gmail.com

Cristina Baus ${ }^{a}$

aCenter for Brain and Cognition (CBC), Universitat Pompeu Fabra, Spain

'ICREA, Barcelona, Spain

${ }^{a}$ Basque Center on Cognition, Brain and Language (BCBL)

Corresponding author at: Center for Brain and Cognition (CBC), Speech Production and Bilingualism lab Universitat Pompeu Fabra, Tànger, 122-140, 08018 Barcelona, Spain.

\begin{abstract}
The information we obtain from how speakers sound - for example their accent—affects how we interpret the messages they convey. A clear example is foreign accented speech, where reduced intelligibility and speaker's social categorization (out-group member) affect memory and the credibility of the message (e.g., less trustworthiness). In the present study, we go one step further and ask whether evaluations of messages are also affected by regional accents - accents from a different region than the listener:. In the current study, we report results from three experiments on immediate memory recognition and immediate credibility assessments as well as the illusory truth effect. These revealed no differences between messages conveyed in local - from the same region as the participant - and regional accents - from native speakers of a different country than the participants. Our results suggest that when the accent of a speaker has high intelligibility, social categorization by accent does not seem to negatively affect how we treat the speakers' messages.
\end{abstract}

Keywords: Regional accent; Intelligibility; Social categorization; Memory recognition; Credibility; Illusory truth

\section{Introduction}

We obtain many sorts of information from the way a speaker sounds, affecting how we remember and evaluate speakers and their messages (e.g., Baus, Bas, Calabria, \& Costa, 2017; Lev-Ari \& Keysar, 2010, 2012; McAleer, Todorov, \& Belin, 2014; Ryan, Giles, \& Sebastian, 1982). One of the most salient features of a spoken message is the accent with which it is conveyed, which influences listeners' evaluations. For instance, messages said in a foreign accent are remembered in less detail and are considered less credible than those produced with a native accent (Evans \& Michael, 2014; Hanzlíková \& Skarnitzl, 2017; Lev-Ari \& Keysar, 2010, 2012; and Podlipský, Šimáčková, \& Petráž, 2016; but see Souza \& Markman, 2013 and Stocker, 2017). Put simply, we do not remember or believe messages produced by foreign accented speakers - i.e., non-native speakers of a language - to the same extent as those produced by native speakers. This has important implications for our everyday interactions, since we often interact with people from other regions with different accents.

Here, we explore whether this reduction in memory and credibility is also present in an even more common conversational situation: interacting with someone with a different regional accent. Regional accents are those accents that mark the speaker's region of origin, but are still native accents. For example, people from Texas in the USA and from Liverpool in the UK have different regional accents, but both are native speakers of English. As we argue below, there are similarities and differences between foreign and regional accents, which are especially relevant when assessing the generalization of accent effects on message processing. In the following, we describe the two main explanations (not mutually exclusive) why foreign accents affect memory and credibility — intelligibility reduction and social categorization — and how they might apply to regional accents.

Processing accented speech involves somewhat a reduction in message intelligibility, which affects cognitive judgments such as the credibility of the message (i.e., processing fluency hypothesis; Oppenheimer, 2008). For instance, several studies support the claim that processing difficulty is directly related to the truth value assigned to the message. The easier to process, the easier to remember, and the more credible a message is considered (Lev-Ari \& Keysar, 2010, 2012; Reber \& Schwarz, 1999). Lev- 
Ari and Keysar showed that listeners remember trivia statements less accurately (Lev-Ari \& Keysar, 2012) and evaluate them as less credible (Lev-Ari \& Keysar, 2010) when produced with a foreign accent than when they are produced with a native accent. Importantly, foreign accents only affect memory when participants are instructed to perform a comprehension task, but not when instructed to perform a memory task (Lev-Ari \& Keysar, 2012). This result is interpreted as showing that the difficulty associated with processing foreign accents comes not only from a reduced intelligibility but from the linguistic expectations created by listeners about speakers (i.e., foreign speakers make more errors), leading to a less detailed processing and weaker memory representations.

The reduction in intelligibility associated with foreign accents may be taken to indicate reduced linguistic ability, and therefore a proxy for unrelated skills such as intellectual ability, much like a "halo effect" (cognitive bias in which an observer's impression of a person influences the evaluation of their individual traits, Nisbett \& Wilson, 1977). That is, accent serves as a cue that a speaker is a non-native speaker, which activates stereotypes-such as foreign accented speakers are less competent and trustworthy than native speakers - which might lead to difficulties in comprehension (Kavas \& Kavas, 2008; Lambert, Hodgson, Gardner, \& Fillenbaum, 1960; Munro \& Derwing, 1995; Ryan et al., 1982). Furthermore, nonnative speakers also evaluate other non-native speakers more negatively (Hanzlíková \& Skarnitzl, 2017; Podlipský et al., 2016), highlighting the importance of nativeness in credibility ratings.

The second reason why foreign accents are remembered less accurately and sound less credible than native accents is social categorization. Foreign accented speakers are categorized as out-group members, and this entails a series of cognitive biases (e.g., "the other accent effect"; Stevenage et al., 2013). In particular, categorizing a speaker as an out-group member may reduce the attention we pay to them and to their messages, resulting in a less detailed memory representation and a reduction in confidence (Sporer, 2001) you do not belong to my social group, so I don't trust you.

Regional accents differ somewhat from foreign accents in the described characteristics. For one thing, regional accents often affect comprehension, although to a lesser extent than foreign accents do (e.g., Floccia, Goslin, Girard, \& Konopczynski, 2006; Goslin, Duffy, \& Floccia, 2012; Brunellière \& SotoFaraco, 2013). Importantly, even if intelligibility is affected, this cannot be interpreted as reduced linguistic competence, since regional accents respond to geographical variables - people with an unfamiliar regional accent come from a different region or country - and not to intellectual ones (although regional accents vary in terms of prestige, see below). Hence, to the extent that the origin of this foreign accent effect is tied to a reduction in intelligibility that signals reduced competence, one may expect memory and credibility effects to diminish or even disappear with regionally accented messages - why should an American consider a British speaker less linguistically skilled and hence less intelligent because of his accent?

In contrast, regional accents do certainly signal that the speaker is an out-group member in terms of both heritage and language use- - e.g., the speaker is from the UK and not from the US. Could this social categorization lead to a reduction in memory and credibility? In fact, we do have some indirect evidence to answer this question. Interactions matching the listener's own accent increase customer satisfaction with the company and purchase intention (Mai \& Hoffmann, 2011), as well as memory for the product name (Morales, Scott, \& Yorkston, 2012).

One of the problems when exploring the impact of regional accents is that sometimes they are also associated with prestige, which affects the way the message is considered. For example, more prestigious accents - e.g., standard accents - lead to greater satisfaction with the individual (Mai \& Hoffmann, 2011) and increased product preference (Morales et al., 2012). Other studies have supported the idea that prestigious accents lead to higher assessments of competence and respectability (St. Clair \& Giles, 1980), as well as social attractiveness and positive personality characteristics (Fuertes, Potere, \& Ramirez, 2002). In fact, the importance of prestige is clear when considering that indeed American listeners judge British accents as more prestigious than American ones, despite the latter being the listener's own-accent (Stewart, Ryan, \& Giles, 1985). Thus, when considering the effect of regional accent, it is important to control for other factors, such as prestige, that might play an important role during the evaluation of the speaker's message.

In sum, given the similarities and differences between foreign and regional accents in terms of intelligibility and categorization, it is not immediately obvious that regional accents affect the memory and credibility of messages in the same way that foreign accents do. The goal of this study is to explore these issues. Specifically, we focus on the particular case of regional accents from different countries-i.e., 
Spanish speakers from Spain versus Spanish speakers from Latin-America-in order to look at regional accents that are both the most distinct and the most culturally distant. At the same time, to reduce the impact of prestige in the present study, we selected accents from Latin-America that tend to be minimally associated with low-prestige stereotypes.

\subsection{The current study}

We assessed the memory and credibility afforded to statements presented in local or regional accents in three experiments. In Experiment 1, we presented statements that were presumably unknown to the participants, and subsequently assessed their ability to recognize them in an old/new paradigm. Following Lev-Ari and Keysar (2012), memory was assessed indirectly. Participants were instructed at the beginning of the experiment that they would be performing a comprehension task. Additionally, the same materials were tested directly in a memory task to discard the possibility that the foreign accent effect was uniquely due to intelligibility differences between accents. In Experiment 2, participants assessed how credible these same statements were, immediately after hearing them once. Finally, in Experiment 3, we measured credibility in a more indirect way by assessing the influence of regional accents on the illusory truth effect. Illusory truth refers to the observation that (among other things) repeating a statement makes it sound more truthful. All the experiments were conducted in Spanish, with the Barcelona accent as the local and various Latin-American accents as the regional ones.

To advance the results, we found that regional accents do not impact the memory or credibility of the message and lead to similar levels of illusory truth than the listener's own accent.

\section{Experiment 1: memory for local and regional accents}

The purpose of Experiment 1 was to explore whether people remember phrases said in regional accents as much as those in the local accent, by having participants listen to statements and then assess whether they had heard them before in an old/new paradigm. Importantly, memory was evaluated following the procedure in Lev-Ari and Keysar (2012). That is, participants were instructed at the beginning of the experiment that their task would be a comprehension task. In doing so, we were able to distinguish if differences in accent are due to speaker-induced expectations or to reduced intelligibility of regional relative to local accents.

\subsection{Methods}

\subsubsection{Participants}

Thirty native Spanish speakers from Barcelona (six male), students at Universitat Pompeu Fabra, took part in this study. Their average age was $22.3(S D=4.6)$. Participation was voluntary and compensated with $5 €$ for $30 \mathrm{~min}$ of participation. Due to technical issues, one participant had to be excluded from the experiment, leaving a final pool of 29 participants.

\subsubsection{Materials}

Sixty sentences were created using trivia facts (translated and reworded from various trivia websites), avoiding geographic and historic trivia from Latin-America and Spain. In order to be able to ask participants about whether they had seen a phrase or not in a recognition task, we had to create foils that they had not been exposed to before-new statement-but that were very similar to the repeated - oldstatements. As a first step for creating the foils, the sentences were worded such that the key word was the last word in the sentence. For example, "The French gave the name the apple of love to tomatoes" and "In 1719, in North America, there first appeared potatoes". Next, in order to create the new statements-foils created for the recognition phase - the last word was switched between pairs of old sentences - which are the statements that had been heard before - creating new phrases with the same words that had been heard before. For example, using the phrases mentioned above, the new sentences would be "The French gave the name the apple of love to potatoes" "In 1719, in North America, there first appeared tomatoes". Importantly, a given participant only received the "old" or "new" version of the sentence and this was counterbalanced across participants.

These statements were recorded from 20 native Spanish speakers and had an average length of $3162 \mathrm{~ms}$. Half of these speakers had the same accent as the participants (namely, the local accent) and the other half had Latin-American accents (the regional accents). Five male and five female speakers were 
recorded in each group. All of the locals were from the Barcelona area with the exception of one female from La Rioja (Spain) and one from Andalusia (Spain), who had been in Barcelona for over 5 years. The regionally accented speakers were from Argentina (3), Chile (2), Colombia (3), Cuba (1), and Peru (1). Recordings were made and edited using Audacity at a rate of $44.1 \mathrm{kHz}$ (32-bit float), with noise removal and normalized $(-1 \mathrm{~dB})$.

\subsubsection{Procedure}

The experiment had two phases: encoding and recognition. Before the encoding phase started, participants were instructed to pay attention to the sentences they were about to hear because they would later be asked to answer some comprehension questions. Then, they were presented with the 60 statements aurally one by one with a $500 \mathrm{~ms}$ silent pause in between. Across participants, sentences were randomized in such a way that no more than three utterances with the same accent were presented in a row-i.e., no more than three local or regional in a row-or two consecutive utterances from the same speaker. After the encoding phase (listening to the sentences) was completed, the recognition phase started. The statements were presented visually and participants were asked to identify whether the presented phrase had appeared before (old) or was new. Participants were presented with 30 statements from the encoding phase and 30 new statements. These were randomized so that no more than three sentences in a row required the same response. A response was required for each phrase.

Once the memory task finished, participants were asked to evaluate the intelligibility (1 to $9-1$ very difficult to understand, 9 extremely clear) and accent (1 to 9-1 Spanish, 9 clearly foreign/not Spanish) of each speaker, by listening again to one exemplar from each voice they heard during the encoding phase.

\subsection{Data analysis}

Two participants were excluded for having a recognition score $(<62 \%$ correct recognition) two standard deviations below the overall mean $(M=85 \%, S D=11 \%)$. Depending on the type of trial (old $/$ new) and the response of the participant (correct/error), four types of responses were coded (see Table 1 and Fig. 1 for the distribution of responses): hits (old trial, correct response), misses (old trial, error), correct rejections (new trial, correct response), and false alarms (new trial, error).

Table 1 Ratings in Experiment 1 for old (hits/miss) and new statements (correct rejections/false alarms). Standard errors in parenthesis. D' values for local and regional accents. Accent effects are calculated as the difference in memory recognition between local and regional messages.

\begin{tabular}{|l|l|l|l|l|l|}
\hline \multicolumn{1}{|c|}{$\begin{array}{c}\text { Memory } \\
\text { recognition }\end{array}$} & \multicolumn{1}{|c|}{ Hit } & \multicolumn{1}{|c|}{ Miss } & $\begin{array}{l}\text { Correct } \\
\text { rejection }\end{array}$ & $\begin{array}{c}\text { False } \\
\text { alarm }\end{array}$ & \multicolumn{1}{|c|}{$\mathrm{A}^{\prime}$} \\
\hline Local & $\begin{array}{l}0.88 \\
(0.09)\end{array}$ & $\begin{array}{l}0.11 \\
(0.09)\end{array}$ & $0.82(0.14)$ & $0.17(0.17)$ & $\begin{array}{l}0.90 \\
(0.06)\end{array}$ \\
\hline Regional & $\begin{array}{l}0.87 \\
(0.12)\end{array}$ & $\begin{array}{l}0.12 \\
(0.12)\end{array}$ & $0.83(0.17)$ & $0.16(0.17)$ & $\begin{array}{l}0.90 \\
(0.08)\end{array}$ \\
\hline Accent effect & & & & & $\mathbf{0 . 0 0 2}$ \\
\hline
\end{tabular}




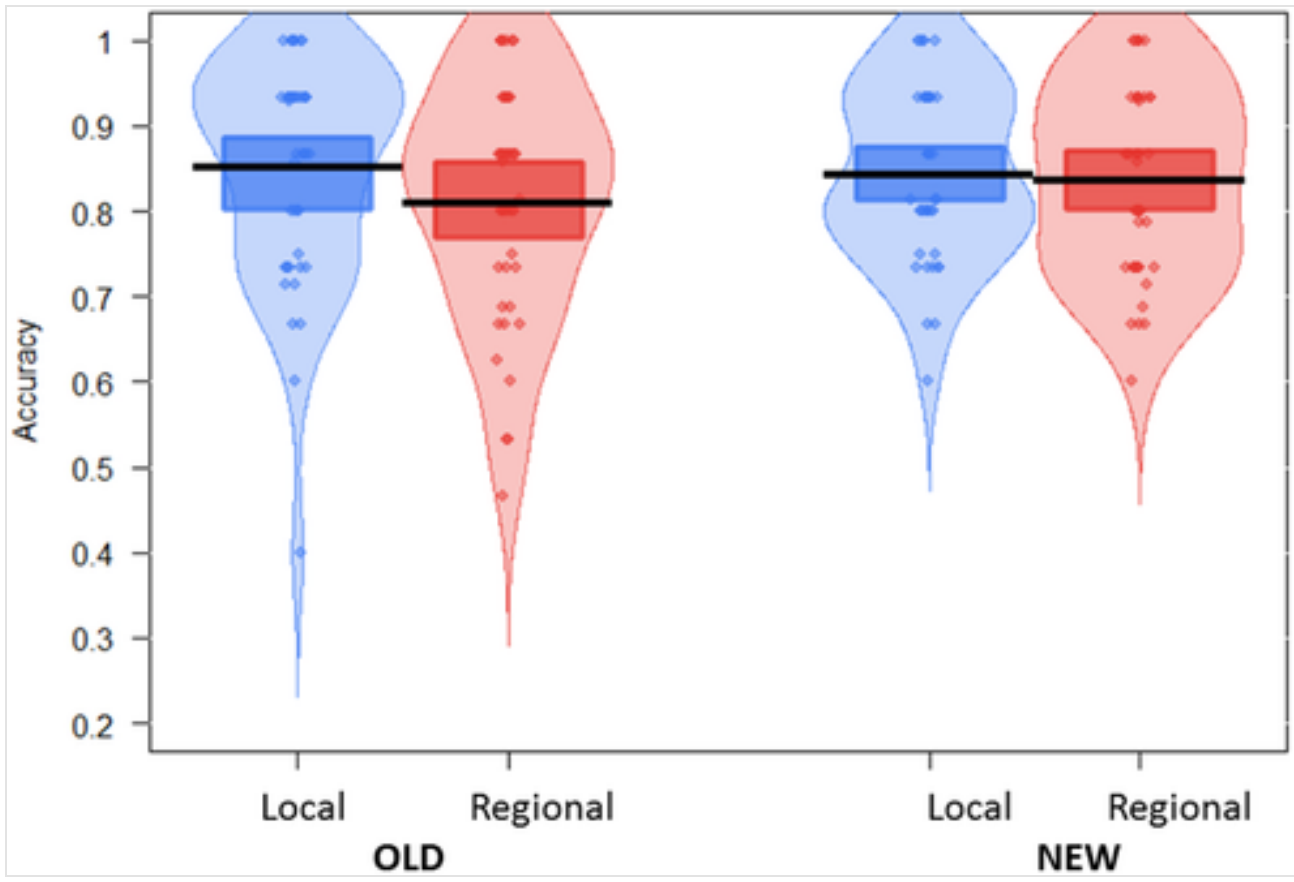

Fig. 1 Pirate plot (“yarrr” R library) for accuracy for New and Old trials, for Local (blue envelopes) and Regional accents (red envelopes). Black lines represent the average accuracy. Colored boxes represent the inference band $(95 \% \mathrm{HDI})$ and beans represent the density of datapoints. (For interpretation of the references to colour in this figure legend, the reader is referred to the web version of this article.)

Different statistical analyses were carried out. Firstly, the A', an index of sensitivity (nonparametric), was calculated for local and regional accents considering hits and false alarms (see Pallier, 2002for A' calculation). The same comparison was submitted to a Bayesian pairwise t-test analysis (JASP Team, 2016) to determine the robustness of the hypotheses. Secondly, accuracy data for old and new trials and for local and regional accents (see Figs. 2 and 3) were modeled by means of a multiple logistic regression analysis with the lme4 library in R (Bates, Maechler, \& Dai, 2008; see also Baayen, Davidson, \& Bates, 2008; R Development Core Team, 2010; Jaeger, 2008). Different models were compared step-wise by means of log likelihood tests to identify the optimal linear mixed-effects model. The final model included trial (Old vs. New), accent (Local vs. Regional), and the interaction between them as fixed effects and participants and items as random effects (the model was not significantly better than the model not including the interaction, $\chi^{2}=0.8$ ). Coefficient estimates and Wald's $Z$ statistics are reported in the results section. Finally, intelligibility and accentedness ratings were evaluated for local and regional accents. 


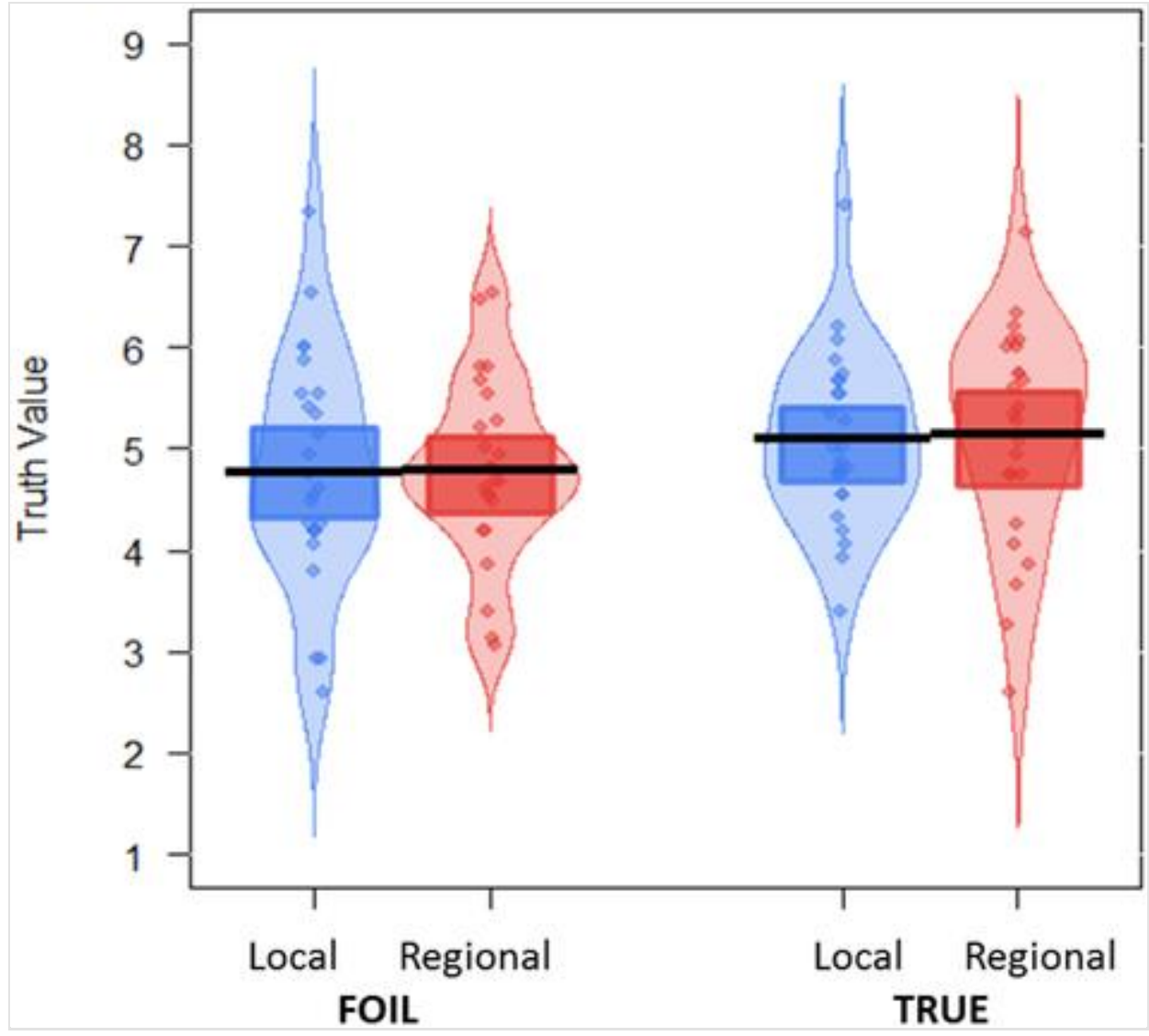

Fig. 2 Pirate plot (“yarrr” R library) for Truth Value responses for False (foils) and True statements, for Local (blue envelopes) and Regional accents (red envelopes). Black lines represent the average accuracy. Colored boxes represent the inference band $(95 \% \mathrm{HDI})$ and beans represent the density of data points. (For interpretation of the references to color in this figure legend, the reader is referred to the web version of this article.) 


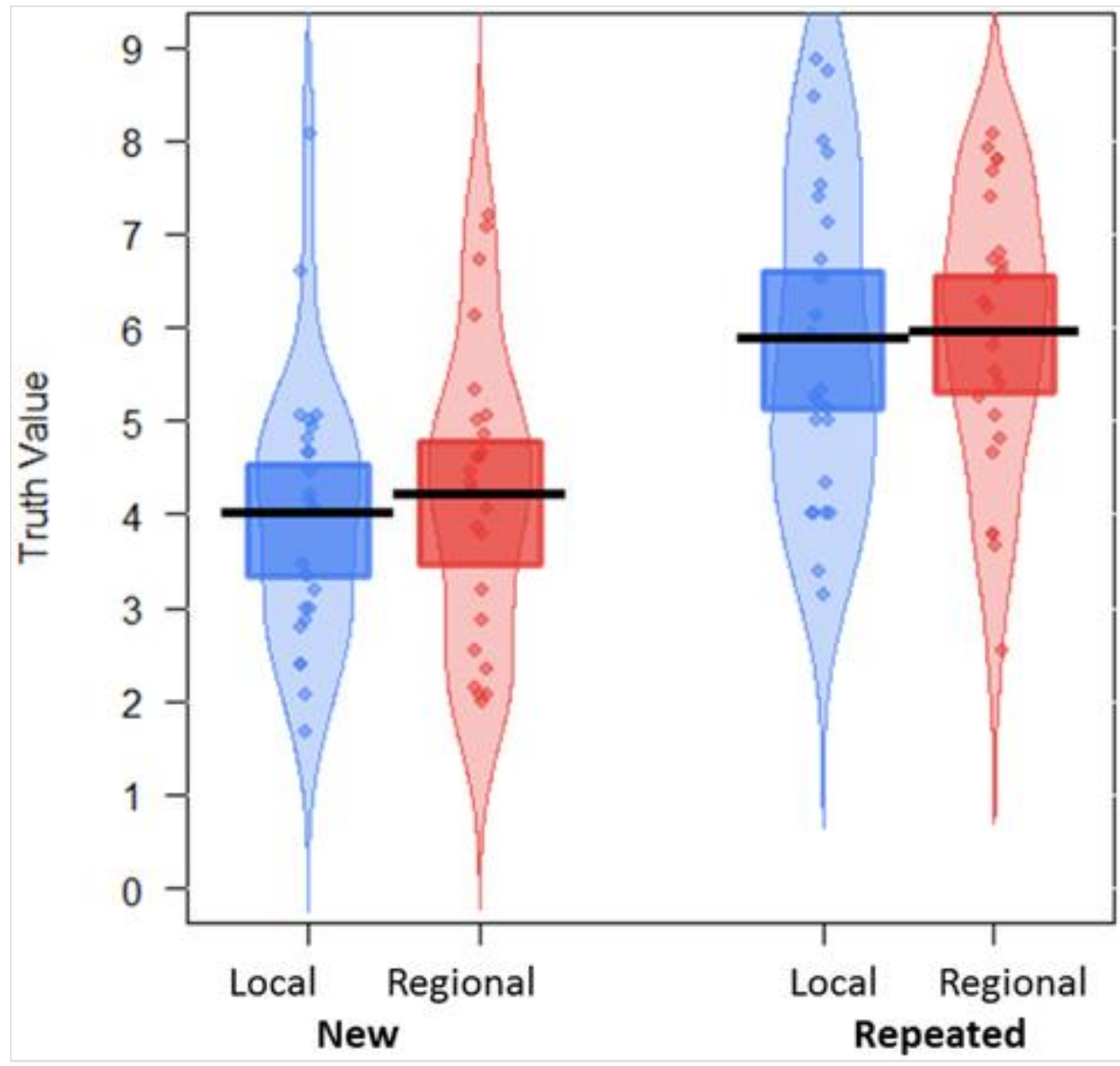

Fig. 3 Pirate plot ("yarrr" R library) for Truth Value responses for New and Repeated statements, for Local (blue envelopes) and Regional accents (red envelopes). Black lines represent the average accuracy. Colored boxes represent the inference band $(95 \% \mathrm{HDI})$ and envelopes represent the density of data points. (For interpretation of the references to color in this figure legend, the reader is referred to the web version of this article.)

Intelligibility Manipulation Check. Following the procedure by Lev-Ari and Keysar (2012), a baseline experiment was also conducted, in which participants were asked to perform the same task (old/new task) with the only difference that they were instructed that they would have a memory test at the end. If the results obtained with foreign-accented speech (Lev-Ari \& Keysar, 2012) apply to regional accents as well, while regional accents should be perceived as less intelligible and more accented than local accents, the accent should not affect people's memory performance when receiving memory instructions. Thus, the memory-instructed task served us mainly as an intelligibility manipulation check to discard that differences between accents are uniquely due to intelligibility differences between regional and local accents.

In the memory task, a new group of 42 native Spanish speakers from Barcelona (seven male) was tested and the average age was $21.24(S D=1.97)$. The experiment was exactly the same as Experiment 1 , with the exception that participants were instructed at the beginning that they would be performing a memory task. Replicating previous results (Lev-Ari \& Keysar, 2012), we did not obtain any trace of accent in the memory recognition when participants were instructed to perform the memory task $(t(41)=1.2, p=.2$; Cohen's d =0.18; Local: $M=0.90, S D=0.07$; Regional: $M=0.88, S D=0.07)$. Intelligibility and accent ratings revealed that regionally accented voices were evaluated as less intelligible (Regional: $M=7.77$, $S D=0.98$, Local: $M=8.12, S D=0.87 ; t(43)=-3.49, p=0.001, d=0.53)$ and more accented than locally accented voices (Regional: $M=6.32, S D=1.23$, Local, $M=2.95, \quad S D=1.49 ; \quad t(43)=9.19$, $p<0.001, d=1.39)$. These results confirm the hypothesis that intelligibility differences alone cannot account for differences in memory between regional and local accents. In addition, these results confirm that the statements and the voices employed were properly selected in terms of difficulty (A' scores were overall high; Local: $M=0.90, S D=0.07$; Regional: $M=0.88, S D=0.07$ ) and prestige. 


\subsection{Results}

Sensitivity index. In the comprehension-instructed task, $\mathrm{A}^{\prime}$ scores for Regional and Local accents were high overall (Local: $M=0.909, S D=0.06$; Regional: $M=0.907, S D=0.08$ ) and did not differ from each other $(t(27)=0.17, p=.8$; Cohen's $d=0.03)$. A Bayesian analysis (paired sample $t$-test) on the effect of accent revealed moderate evidence for the null hypothesis $\left(B_{01}=4.91\right.$; error $\%=4.46 \mathrm{e}-5$; with less than 1 being no evidence, $1-3$ being anecdotal evidence, $3-10$ being moderate evidence, and 10 and above being strong evidence according to Lee \& Wagenmakers, 2014).

Logistic regression model. Accuracy data from 60 items and 28 participants were considered in the analysis (intercept from new trials with local accent, $\beta=1.89$ ). Results revealed that participants were more accurate at recognizing old than new items $(\beta=0.53 ; S E=0.21 ; Z=2.4 ; p=.01$; power for the factor with 95\% confidence interval: $100 \%$ [60-100]), ${ }^{1}$ but equally accurate at recognizing statements presented with the local accent or with the regional ones $(\beta=0.08 ; S E=0.20 ; Z=-0.4 ; p=.6$; power $20 \%[2.5-55.6])$. The interaction between trial and accent was not significant $(\beta=-0.1 ; \mathrm{SE}=0.31 ; Z=-0.3 ; p=.7$; power $20 \%$ [2.5-55.6]), showing no differences between accents neither for old nor for new items.

Intelligibility and accent ratings. When considering intelligibility and accent ratings, intelligibility was high overall, with an average score of $7.93(S D=1.03)$. While participants tended to rate regional accents as less intelligible than local ones, such difference was not statistically significant, (Regional: $M=7.7, S D=0.98$; Local: $M=8.1, S D=1.29 ; t(24)=-1.7, p=.1$ ). Regional voices were rated as significantly more accented than local voices $(t(24)=13.1, p<.001$; Regional: $M=7.1, S D=1.3$; Local: $M=1.90, S D=0.7$ ). Finally, to explore if accuracy (collapsed for old and new statements) was influenced by intelligibility or accentedness, correlation analyses were conducted. No significant correlation was obtained between intelligibility and memory recognition $\left(r(58)=-0.18, p=.16 ; \mathrm{B}_{01}=2.44\right)$. In contrast, for accentedness, there was a trend for more accented statements being more accurately memorized than less accented statements $\left(r(58)=0.24, p=.06 ; \mathrm{B}_{01}=1.11\right)$. Additionally, correlation analyses revealed that intelligibility and accent were not significantly correlated for all voices together $(r(18)=-0.39, p=.09$, $\left.\mathrm{B}_{01}=1.28\right)$ nor for regional or local individually $\left(r(8)=-0.06, p=.86, \mathrm{~B}_{01}=3.21\right.$ and $r(8)=-0.42, p=.23$, $\mathrm{B}_{01}=1.93$, respectively) revealing that variations in intelligibility were not caused by accent strength.

The results show that while regional accents were evaluated as less intelligible and more accented than local accents, memory performance was comparable for statements presented in a local and a regional accent. This was observed regardless of whether participants were explicitly warned they would be tested for their memory or not (i.e., by doing a comprehension task). These results contrast with those in the LevAri and Keysar (2012) study with foreign accents. In their study, an effect of accent was obtained in the comprehension but not the memory task. Thus, the interpretation that differences in memory between native and accented speech are due to interactional expectations (i.e., accented speakers are expected to make mistakes) does not hold for regional accents. Despite regional accents being evaluated as less intelligible than local accents, intelligibility had no impact on the accuracy with which statements were memorized as revealed by the correlation analysis. Thus, even if regional accents might entail a reduction in intelligibility, this cannot be interpreted as a sign of reduced linguistic competence, leading to vaguer memory. Similarly, even if participants categorized voices according to their accent (e.g., Stevenage et al., 2013), this did not result in a memory advantage for in-group voices.

To sum up, in Experiment 1 we showed that messages are memorized with the same detail regardless of whether they were produced with a regional or a local accent. In Experiment 2, we tested whether regional accents affect the credibility of a message.

\section{Experiment 2: credibility for local and regional accents}

The purpose of Experiment 2 was to assess whether there is an effect of accent on credibility by comparing the truth value of statements produced with local and regional accents.

\subsection{Methods}

\subsubsection{Participants}


Twenty-five Spaniard participants took part in this study (nine male) and the average age was 23.47 $(S D=6.74)$. None of the participants had taken part in Experiment 1 but were from the same participant pool, had a similar linguistic profile, and were compensated the same way.

\subsubsection{Materials}

Materials were the same as in Experiment 1. The only difference was that new sentences from Experiment 1 were used as foils here. That is, here we intermixed true and false statements.

\subsubsection{Procedure}

Participants were presented 60 statements (30 true and 30 foils) aurally and after each phrase were asked to identify how true it was on a scale from 1 to 9 ( 1 being false and 9 being true). An answer was required for each statement. As mentioned for Experiment 1, each statement had a true (e.g., "The French gave the name the apple of love to tomatoes") and a foil version (e.g., "The French gave the name the apple of love to potatoes"), but participants received only one of the versions to avoid repetition effects and this was counterbalanced across participants. Sentence presentation was randomized such that no more than three utterances from the same accent appeared in a row, no more than three statements in a row were true or false, and no two consecutive utterances were from the same speaker.

After the main task, participants rated intelligibility and accent of the statements as in Experiment 1.

\subsection{Results}

Linear mixed model. Data was analyzed by fitting a generalized linear mixed model analysis in R. The final model included accent (Local vs. Regional), truth value (True vs. Foil), and the interaction between them as fixed factors and participants and items as random factors (no significant differences with the model not considering the interaction; $\chi^{2}=0.19$ ). Data from 60 items and 25 participants were considered (intercept $=4.79$ ). Responses were mostly "I don't know" responses (around 5 in the $1-9$ scale). True sentences had a slightly higher truth-value than foils $(\beta=0.26$; $S E=0.18 ; t=1.4, p=.1$; power $80 \%$ [44.397.4]), although the difference did not reach significance. However, results revealed neither a difference between accents $(\beta=-0.01 ; S E=0.18 ; t=0.09, p=.9$; power $10 \%$ [0.2-44.5]) nor an interaction with truthvalue $(\beta=0.11 ; S E=0.25 ; t=0.4, p=.6)$. These results were further validated in a two-way Bayesian Repeated Measures ANOVA with accent (Local vs. Regional) and truth-value (True vs. Foil) as the independent variables. Bayes factors revealed moderate evidence for the alternative hypothesis when truthvalue was considered $\left(\mathrm{B}_{01}=0.54\right.$; error $\left.\%=0.8\right)$ and moderate evidence for the null hypothesis in the case of accent $\left(\mathrm{B}_{01}=4.6\right.$; error $\left.\%=1.8\right)$.

Intelligibility and accent ratings. When considering intelligibility and accent ratings, although there was a tendency for evaluating regional accents as less intelligible, there was no significant difference (Regional: $M=7.86, S D=0.98$; Local: $M=8.01, S D=1.29 ; t(24)=-0.79, p=.44, d=0.16$ ). There was a significant difference for accent, $(t(24)=21.97, p<.001, d=4.41)$, with local accents being rated as less accented than regional accents $(M=1.90, S D=0.82$ and $M=7.07, S D=0.64$, respectively). To explore if the truth value of statements was determined by intelligibility or accentedness, correlation analyses were conducted. No significant correlation was obtained for intelligibility $\left(r(58)=-0.07, p=.5 ; \mathrm{B}_{01}=2.3\right)$. In contrast, accentedness was positively correlated with truth value, such that the more accented a statement was, the more credible it was considered $\left(r(58)=0.29, p=.02 ; \mathrm{B}_{01}=0.4\right)$. Intelligibility and accent were not significantly correlated for all voices together $\left(r(18)=-0.15, p=.52, \mathrm{~B}_{01}=3.65\right)$ nor for regional and local individually $\left(r(8)=0.17, p=.64, \mathrm{~B}_{01}=3.00\right.$ and $r(8)=-.55, p=.10, \mathrm{~B}_{01}=1.21$, respectively) revealing that variations in intelligibility were not caused by accent strength.

Table 2 Credibility ratings (scale 1-9) for true and false statements. Standard errors in parenthesis. Credibility effects are calculated as the difference between true and false statements. Accent effects are calculated as the difference between local and regional ratings.

\begin{tabular}{|l|l|l|l|}
\hline \multicolumn{1}{|c|}{ Credibility } & True statement & False statement & Credibility effect \\
\hline Local & $5.14(1.07)$ & $4.80(0.89)$ & 0.34 \\
\hline
\end{tabular}




\begin{tabular}{|l|l|l|l|}
\hline \multicolumn{1}{|c|}{ Credibility } & \multicolumn{1}{|c|}{ True statement } & \multicolumn{1}{|c|}{ False statement } & \multicolumn{1}{c|}{ Credibility effect } \\
\hline Regional & $5.09(0.85)$ & $4.78(1.13)$ & 0.31 \\
\hline Accent effect & $\mathbf{0 . 0 5}$ & $\mathbf{0 . 0 2}$ & $\mathbf{0 . 0 3}$ \\
\hline
\end{tabular}

Table 3 Truth ratings (scale 1-9) for new and repeated statements. Standard errors in parenthesis. Truth effects are calculated as the difference between repeated and new statements. Accent effects are calculated as the difference between local and regional ratings.

\begin{tabular}{|c|c|c|c|}
\hline Illusory truth & New & Repeated & Truth effect \\
\hline Local & $4.03(2.8)$ & $6.06(2.9)$ & 2.03 \\
\hline Regional & $4.16(2.9)$ & $5.78(2.9)$ & 1.62 \\
\hline Accent effect & -0.13 & 0.28 & 0.4 \\
\hline
\end{tabular}

This experiment shows that accent does not influence the likelihood that someone believed the statements or not (see Table 2). These results partly replicate the results obtained in the study of Lev-Ari and Keysar (2010) for mild foreign accents. Truth values were similar for native and mild foreign accents when participants were aware that the difficulty of processing accented speech could affect their truth judgements. If, as suggested, the cause of disbelief comes from a "processing difficulty", our results show that such difficulty might be absent for regional accents. Indeed, local and regional accents were evaluated similarly in terms of intelligibility, which supports this hypothesis. The only influence we obtained was for accentedness, although in the opposite direction than expected. More accented statements were evaluated as more credible than less accented ones. This is surprising if we consider that stronger accents should lead to an increase in processing difficulty, affecting the credibility of the message.

Nevertheless, it is important to point out that overall the effects of foreign accent on credibility do not seem very reliable. The effects of foreign accent on credibility have been found in some studies (e.g., Evans \& Michael, 2014; Hanzlíková \& Skarnitzl, 2017; Lev-Ari \& Keysar, 2010, 2012; Podlipský et al., 2016), but not in others (e.g., De Meo, 2012; Souza \& Markman, 2013; Stocker, 2017). Thus, with the present data, we cannot discard the possibility that we did not find a difference between accents in the truth assessments of messages simply because the accent effect is not robust. Part of the problem might stem from the difficulty in assessing the validity of unknown facts. This may have prompted participants to repeatedly give middle truth values to the statements (as if to say "I don't know"). This is what we observed in Experiment 2 and in previous studies as well (e.g., Lev-Ari \& Keysar, 2010).

Perhaps a better and more indirect way of assessing credibility is to explore the presence of the illusory truth effect, which can be created by repeating a statement (see Dechene, Stahl, Hansen, \& Wanke, 2010 for a review). This effect refers to the observation that people tend to consider more truthful statements that they have heard twice, as if encountering the same information repeatedly made it more likely to be true. The presence of this phenomenon is considered to be mediated by implicit memory processes, driven by processing fluency (Begg, Anas, \& Farinacci, 1992). That is, repeating a statement increases its fluency of processing, which leads individuals to rate it as probably true (relative to the first time the statement is encountered). Thus, the illusory truth effect allows us to test in an indirect manner whether people believe statements presented in a local or regional accent to the same extent. That is, the illusory truth effect allows us to reduce the uncertainty of truth values, becoming a more proper test of truth assessment.

\section{Experiment 3: effects of accent on illusory truth}

The purpose of Experiment 3 was to assess whether regional accents indirectly affect truth assessments by testing their modulation of the illusory truth effect. To do so, we manipulated the first exposure to the information by presenting the first statement in one of two types of accent: local or regional. 
Later, all of the statements were presented visually, half of the statements were repeated verbatim (old statements in Experiment 1) and the other half had the last word changed (new statements or foils in Experiment 1). If accent truly affects what we remember or how much credit we give to a statement, it should modulate later responses to the same statement when it is presented in a way that is impartial to accent, i.e., visually.

\subsection{Methods}

\subsubsection{Participants}

Twenty-five Spaniards took part in this study (10 male) and the average age was $24.92(S D=9.21)$. They were from the same participant pool as in Experiments 1 and 2, but had not done either of the prior experiments and were compensated the same way.

\subsubsection{Materials}

The same materials from Experiment 2 were utilized for this experiment.

\subsubsection{Procedure}

The experiment was comprised of two phases. Firstly, participants were aurally presented 30 true statements and 30 foils with $500 \mathrm{~ms}$ of silence in between. Sentences were randomized as in Experiment 2. Participants were told that these were facts they probably did not know and that some were true and some were false. After this phase finished, participants were told to evaluate sentences, ignoring what they had heard before. Participants were visually presented 30 true statements (15 repeated, 15 new) and 30 foils (15 repeated, 15 new) and were asked to identify how true the phrases were on a scale from 1 to 9 (as in Experiment 2). Answers were required for all sentences. These were randomized so that no more than three phrases in a row were repeated/new and no more than three in a row were true/false.

After the main task, participants rated intelligibility and accent as in Experiments 1 and 2.

\subsection{Results}

Generalized linear mixed model. As for Experiment 2, a Generalized Linear Mixed Model analysis was computed to explore illusory truth effects. Different models were compared considering accent, repetition, and truth value. The best fitting model was found when the factors accent, repetition, and the interaction between them were considered as fixed factors and participants and items as random factors $\left(\chi^{2}=143.1, p<.001\right)$. Data from 60 items and 25 participants were considered in the analysis (intercept $=4.01$ ). As expected, an illusory truth effect was observed (see Table 3), where repeated information was considered more truthful than new information $(M=5.9, S D=2.8$ and $M=4.1, S D=2.9$, respectively; $\beta=1.8 ; S E=0.20 ; t=9.06, p<.001$; power $100 \%(69-100)$ ). However, there were no differences between accents $(\beta=0.1 ; S E=0.21 ; t<1$; power $30 \%$ [6.6-65.2]) and they did not modulate the illusory truth effect $(\beta=-0.1 ; S E=0.29 ; t<1)$. These results were further validated by the Bayesian analyses, with the Bayes Factor for repetition $\left(\mathrm{B}_{01}=3 \mathrm{e}-6\right.$; \% $\%$ error $\left.=2.4\right)$ revealing strong evidence for the alternative hypothesis that the two repetition levels were different ${ }_{4}$, and the Bayes Factor for accent $\left(\mathrm{B}_{01}=4.5 ; \%\right.$ error $\left.=1\right)$ showing moderate evidence for the null hypothesis.

Intelligibility and accent ratings. Intelligibility for all voices was high, with an average score of 8.03 $(S D=0.60)$. There was a significant difference in intelligibility between regionally $(M=7.84, S D=0.71)$ and locally accented speakers $(M=8.21, S D=0.67), t(24)=-2.73, p=.01, d=0.54$. In addition, regional speakers were rated as more accented than local speakers $(M=6.87, S D=0.98$ and $M=1.74, S D=0.74$, respectively; $t(24)=20.25, p<.001, d=4.08)$. Neither intelligibility $\left(r(58)=-0.02, p=.8, \mathrm{~B}_{01}=6.1\right)$ nor accentedness $\left(r(58)=-0.11, p=.3, \mathrm{~B}_{01}=4.2\right)$ correlated with truth value judgments. In addition, intelligibility and accent were not significantly correlated, neither when all voices were considered together $\left(r(18)=-0.32, p=.18, \mathrm{~B}_{01}=1.95\right)$ nor for regional $\left(r(8)=0.01, p=.99, \mathrm{~B}_{01}=3.23\right)$, but they were for local $\left(r(8)=-0.71, p=.02, \mathrm{~B}_{01}=0.44\right)$. This reveals that variations in intelligibility for regional accents were not caused by regional accent strength.

The results of this experiment show that while regional and local accents were assessed differently on intelligibility, neither accent nor intelligibility modulated the illusory truth effect. As expected, statements were evaluated as more truthful when presented a second time, which supports the robustness of the illusory truth effect (e.g., Bacon, 1979; Hasher, Goldstein, \& Toppino, 1977). If we consider that such effect comes 
from an increase in processing fluency, our results further support the idea that regional and local accents were not different in terms of difficulty and therefore, there was no room for improvement when information was repeated.

Considering Experiments 2 and 3 together, our results show that regardless of whether credibility was tested directly or indirectly (through the illusory truth effect), regional accents do not have any impact on how credible a message is evaluated. The lack of an accent effect cannot be attributed to intelligibility (Lev-Ari \& Keysar, 2010), since regional accents were rated as less intelligible in Experiment 3 but not in Experiment 2. Additionally, as we argued for Experiment 1, even if regionally accented speakers were categorized as out-group, this had no influence on how credible statements were considered.

Overall, the results of the three studies show no effect of accent on memory and credibility of messages. Despite participants clearly identifying the accent of speakers and sometimes considering them less intelligible, this had no impact on memory and credibility.

\section{General discussion}

We assessed the impact of regional accents on the recognition and credibility of messages. Results from three experiments revealed no effect of accent on memory and credibility. That is, listeners remember and believe speakers' messages similarly regardless of their accent, both when explored directly and indirectly, through the illusory truth effect.

These results contrast with some studies on foreign accents, where credibility and memory for messages seem to be reduced as compared to native accents (Lev-Ari \& Keysar, 2010, 2012). Results are also surprising in light of research showing that speakers with standard accents are considered more competent and prestigious (e.g., Bishop, Coupland, \& Garrett, 2005; Giles, 1970, 1971, 1973; Grondelaers \& Van Hout, 2010; Grondelaers, Van Hout, \& Steegs, 2010). Furthermore, one might expect at least the credibility of the message to be higher when it is produced with the accent that participants were most accustomed to, which could mark the verbal norm for them. However, this is not the case, showing that a person's assessment of a speaker can be independent of her assessment of the message.

Our observations do not imply that any regional accent would lead to the same results. In particular, one feature of our study may be crucial when assessing the generalization of these results: intelligibility. In the Introduction we argue that a reduction in intelligibility may be taken as an indicator of linguistic competence, and that this index could then be extrapolated to general intellectual ability. We further argue that when intelligibility is high or cannot be attributed to linguistic competence, as is the case with regional accents, then this "halo" effect may be reduced in comparison to foreign accents (Lev-Ari \& Keysar, 2012). If so, the credibility of the message should be comparable for local and regional accents, which is what we found. Both types of accents had high intelligibility scores in our study (around 8 on a 1-9 scale), which might have reduced the room for finding an effect of accent on memory and credibility. ${ }^{2}$ However, it is possible that a study using less intelligible regional accents may find differences in memory and credibility, especially if listeners relate intelligibility to linguistic ability. If accents are on a continuum of intelligibility, with native and foreign accents standing at the two end-points and regional accents somewhere in between (see Floccia et al., 2006), the effects of regional accents might depend on where they are placed on the scale of intelligibility. Note that while the evidence for the effects of accent on memory is rather limited, making it more difficult to discuss the reliability of the phenomenon, our results are in line with several studies that failed to replicate the effect of foreign accent on credibility (e.g., De Meo, 2012; Souza \& Markman, 2013; Stocker, 2017). Thus, at least for credibility, intelligibility does not seem to be the only factor. As mentioned above, part of the problem with this task might stem from the fact that participants provided mostly "I do not know" responses and leaving little room to capture differences in truth assessments. However, the fact that no regional effect was obtained when credibility was assessed indirectly through the illusory truth effect suggests that indeed regionally accented messages did not entail a processing difficulty for participants.

Our results also show that social categorization as an out-group member does not necessarily lead to a reduction in memory or credibility. Yet, this does not mean that social categorization prompted by accent has no effect on these two variables. On the contrary, this parameter may be significant when accents are interpreted according to prestige. This is especially the case for some speaker judgments (e.g., hirability, competence) that are not related to the ingroup/outgroup distinction, but rather to the accent's prestige. For example, Americans consider British accented speakers to be more intelligent and of higher social status 
than American accented speakers and French-speaking Belgian participants perceive speakers from France as more competent than Belgian French speakers (Stewart et al., 1985; Yzerbyt, Provost, \& Corneille, 2005). However, our results do not address the effect of prestige, since we selected Latin-American accents with relatively high prestige, predominantly speakers from Chile and Argentina. Perhaps using regional accents with lower prestige would show different results. However, this is beyond our scope, as we focused on the effects of regional accents and not of prestige.

To conclude, messages presented in regional accents with high intelligibility and reasonable prestige are remembered and believed similarly to those presented in local accents. This shows that having a regional accent different from the local one does not necessarily have negative consequences, suggesting that social categorization per se is not enough to affect how we treat a speaker's messages. This, of course, has important implications for social issues such as hiring teachers and representatives.

\section{Uncited reference}

Moy and Ng, 1996

\section{Acknowledgements}

CF is now supported by a MINECO predoctoral grant for predoctoral researchers from the Spanish government (BES-2016-077169). AC was supported by two grants from the Spanish Government, PSI2011-23033, PSI2014-52181-P, a grant from the Catalan Government (AGAUR SGR 268) and a grant from the European Research Council under the European Community's Seventh Framework Programme (FP7/2007-2013 Cooperation grant agreement $\mathrm{n}^{\circ}$ 613465-AThEME). CB was supported by the People Program (Marie Curie Actions, FP7-PEOPLE 2014-2016) under REA agreement n ${ }^{\circ} 623845$ and now is supported by the program Beatriu de Pinòs from the Catalan Government.

\section{References}

Baayen R.H., Davidson D.J. and Bates D.M., Mixed-effects modeling with crossed random effects for subjects and items, Journal of Memory and Language 59 (4), 2008, 390-412.

Bacon F.T., Credibility of repeated statements: Memory for trivia, Journal of Experimental Psychology: Human Learning and Memory 5 (3), 1979, 241.

Bates D., Maechler M. and Dai B., lme4: Linear mixed-effects models using s4 classes, version 0.999375-28. R package, 2008.

Baus C., Bas J., Calabria M. and Costa A., Speak my language and I will remember your face better: An ERP study, Frontiers in Psychology 8, 2017.

Begg I.M., Anas A. and Farinacci S., Dissociation of processes in belief: Source recollection, statement familiarity, and the illusion of truth, Journal of Experimental Psychology: General 121 (4), 1992, 446.

Bishop H., Coupland N. and Garrett P., Conceptual accent evaluation: Thirty years of accent prejudice in the UK, Acta linguistica hafniensia 37 (1), 2005, 131-154.

De Meo A., How credible is a non-native speaker?, Prosody and surroundings. Methodological perspectives on second language prosody 2012, 3-9.

Dechene A., Stahl C., Hansen J. and Wanke M., The truth about the truth: A meta-analytic review of the truth effect, Personality and Social Psychology Review 14 (2), 2010, 238-257.

Evans J.R. and Michael S.W., Detecting deception in non-native English speakers, Applied Cognitive Psychology 28 (2), 2014, 226-237.

Floccia C., Goslin J., Girard F. and Konopczynski G., Does a regional accent perturb speech processing?, Journal of Experimental Psychology: Human Perception and Performance 32 (5), 2006, 1276-1293.

Fuertes J.N., Potere J.C. and Ramirez K.Y., Effects of speech accents on interpersonal evaluations: Implications for counseling practice and research, Cultural Diversity and Ethnic Minority Psychology 8 (4), 2002, 346356.

Giles H., Evaluative reactions to accents, Educational Review 22 (3), 1970, 211-227. 
Giles H., Patterns of evaluation to RP, South Welsh and Somerset accented speech, The British Journal of Social and Clinical Psychology 10 (3), 1971, 280-281.

Giles H., Communicative effectiveness as a function of accented speech, 1973.

Grondelaers S. and Van Hout R., Is standard Dutch with a regional accent standard or not? Evidence from native speakers' attitudes, Language Variation and Change 22 (2), 2010, 221-239.

Grondelaers S., Van Hout R. and Steegs M., Evaluating regional accent variation in standard Dutch, Journal of Language and Social Psychology 29 (1), 2010, 101-116.

Hanzlíková D. and Skarnitzl R., Credibility of native and non-native speakers of English revisited: Do non-native listeners feel the same?, Research in Language 15 (3), 2017, 285-298.

Hasher L., Goldstein D. and Toppino T., Frequency and the conference of referential validity, Journal of Verbal Learning and Verbal Behavior 16 (1), 1977, 107-112.

Jaeger T.F., Categorical data analysis: Away from ANOVAs (transformation or not) and towards logit mixed models, Journal of Memory and Language 59 (4), 2008, 434-446.

Kavas A. and Kavas A., An exploratory study of undergraduate college students' perceptions and attitudes toward foreign accented faculty, College Student Journal 42 (3), 2008, 879-891.

Lambert W.E., Hodgson R.C., Gardner R.C. and Fillenbaum S., Evaluational reactions to spoken languages, The Journal of Abnormal and Social Psychology 60 (1), 1960, 44.

Lee M.D. and Wagenmakers E.J., Bayesian cognitive modeling: A practical course, 2014, Cambridge university press.

Lev-Ari S. and Keysar B., Why don't we believe non-native speakers? The influence of accent on credibility, Journal of Experimental Social Psychology 46 (6), 2010, 1093-1096.

Lev-Ari S. and Keysar B., Less-detailed representation of non-native language: Why non-native speakers' stories seem more vague, Discourse Processes 49 (7), 2012, 523-538.

Mai R. and Hoffmann S., Four positive effects of a salesperson's regional dialect in services selling, Journal of Service Research 14 (4), 2011, 460-474.

McAleer P., Todorov A. and Belin P., How do you say 'hello'? Personality impressions from brief novel voices, PLoS One 9 (3), 2014, e90779.

Morales A.C., Scott M.L. and Yorkston E.A., The role of accent standardness in message preference and recall, Journal of Advertising 41 (1), 2012, 33-46.

S.H.C

Munro M.J. and Derwing T.M., Processing time, accent, and comprehensibility in the perception of native and foreign-accented speech, Language and Speech 38 (3), 1995, 289-306.

Nisbett R.E. and Wilson T.D., The halo effect: Evidence for unconscious alteration of judgments, Journal of Personality and Social Psychology 35 (4), 1977, 250-256.

Oppenheimer D.M., The secret life of fluency, Trends in Cognitive Sciences 12 (6), 2008, 237-241.

Pallier C., Computing discriminability and bias with the R software, 2002, (Available at http://www.pallier.org/ressources/aprime/aprime.pdf.).

Podlipský V.J., Šimáčková Š. and Petráž D., Is there an interlanguage speech credibility benefit?, Topics in Linguistics 17 (1), 2016, 30-44.

Reber R. and Schwarz N., Effects of perceptual fluency on judgments of truth, Consciousness and Cognition $\mathbf{8}$ (3), 1999, 338-342.

Ryan E.B., Giles H. and Sebastian R.J., An integrative perspective for the study of attitudes toward language variation, Attitudes towards language variation: Social and applied contexts 1982, 1-19.

Souza A.L. and Markman A.B., Foreign accent does not influence cognitive judgments, 2013, (In CogSci). 
Sporer S.L., Recognizing faces of other ethnic groups: An integration of theories, Psychology, Public Policy, and Law 7, 2001, 36-97.

St. Clair R.N. and Giles H., (Eds.), The social and psychological contexts of language, 1980, Lawrence Erlbaum Associates; Hillsdale, N.J..

Stocker L., The impact of foreign accent on credibility: An analysis of cognitive statement ratings in a Swiss context, Journal of Psycholinguistic Research 46 (3), 2017, 617-628.

Stevenage S.V., Neil G.J., Barlow J., Dyson A., Eaton-Brown C. and Parsons B., The effect of distraction on face and voice recognition, Psychological Research 77 (2), 2013, 167-175.

Stewart M.A., Ryan E.B. and Giles H., Accent and social class effects on status and solidarity evaluations, Personality and Social Psychology Bulletin 11 (1), 1985, 98-105.

Yzerbyt V., Provost V. and Corneille O., Not competent but warm... really? Compensatory stereotypes in the French-speaking world, Group Processes \& Intergroup Relations 8 (3), 2005, 291-308.

\section{Footnotes}

${ }^{1}$ Power analyses were calculated in R by means of the package SIMR. A power estimate greater than $80 \%$ is considered necessary to reject the null hypothesis.

${ }^{2}$ Importantly, we found that there was no correlation between intelligibility and accent. Although the power for these tests was small (power of 0.25 on average), we replicated these results in each of the studies, with different subjects. Furthermore, Bayes factors for the correlations between intelligibility and accent showed evidence for the null hypothesis in almost all cases (except for in the case of local accents in Experiment 3) and, in the case of regional accents, consistently showed moderate evidence for the null hypothesis (Bayes factors of 3 or above in all 3 studies). 